\title{
Scaling up mental health care for refugee populations: a model by UNRWA
}

Mio Akita, ${ }^{1}$ Yousef Shahin ${ }^{1}$ and Akihiro Seita ${ }^{1}$

${ }^{1}$ Department of Health, United Nations Relief and Works Agency for the Near East, Amman, Jordan (Correspondence to: Mio Akita mioakitabga@gmail. com).

Citation: Akito M; Shahin Y; Seita A. Scaling up mental health care for refugee populations: a model by UNRWA. East Mediterr Health J. 2021;27(12):11351136. https://doi.org/10.26719/2021.27.12.1135

Received: 20/12/19; accepted: 01/03/20

Copyright (C) World Health Organization (WHO) 2021. Open Access. Some rights reserved. This work is available under the CC BY-NC-SA 3.0 IGO license (https://creativecommons.org/licenses/by-nc-sa/3.o/igo).

Mental health among refugees and displaced populations is one of the main global public health concerns. According to the World Health Organization (WHO) estimates (1), 1 person in 5 among the conflict-affected populations is living with some form of mental disorder and almost 1 in 10 is living with a moderate or severe mental disorder. These figures are much higher than the previous estimates.

In the WHO Region for the Eastern Mediterranean, which houses some of the world's most severeemergencies and protracted crises, the need for mental health care for displaced populations is ever more increasing (2).

After 70 years of ongoing displacement, Palestine refugees remain the largest and longest-standing refugee population in the Region as well as in the world. The protracted conflicts, blockade of Gaza, and deteriorating socioeconomic situation are adversely affecting the mental health of Palestine refugees. In response, in 2017, the United Nations Relief and Works Agency for Palestine Refugees in the Near East (UNRWA) started the implementation of the Mental Health and Psychosocial Support (MHPSS) programme, which could be a scalable model for mental health response for other refugee and displaced populations.

The Agency (UNRWA) provides assistance and protection to 5.7 million Palestine refugees in Jordan, Lebanon, Syria, Gaza and the West Bank (3). As part of its mandate, UNRWA provides primary health care services to the refugee population. In response to the dire need for mental health care, the Agency began a community mental health programme in the West Bank and Gaza in the early 2000s. To mitigate the mental health distress of Palestine refugees in a more comprehensive way in all fields, UNRWA started integrating a new MHPSS programme into its primary health care services in 2017. This was long awaited, but due to financial constraints, it was only made possible by a project fund granted from the Japanese government. All 141 health centres in all 5 fields are providing MHPSS care. A total of 2083 health staff, including doctors, nurses, midwives, paramedical and support staff completed psychosocial support training. In addition, all doctors and staff nurses received training in the WHO Mental Health GAP Action Programme (mhGAP).
With the cooperation from the German Corporation for International Cooperation GmbH (GIZ, Deutsche Gesellschaft für Internationale Zusammenarbeit), UNRWA developed training modules on basic psychosocial support. The modules are designed to equip staff with techniques in various areas, including selfcare, group support sessions, patient protection, genderbased violence, and privacy and confidentiality, as well as dealing with complicated cases. In addition, the mhGAP programme, which is based on the mhGAP Intervention Guide (mhGAP-IG) to diagnose and scale up services for mental, neurological and substance use disorders, especially in low and lower middle income countries, is being used for training of doctors and staff nurses.

Agency-wide, more than 98,401 cases were screened for MHPSS consultations in 2019, and 21,981 positive cases were identified and assisted. In 2020, Health staff managed to screen 50,810 persons out of which 10,838 were identified as positive according to WHO standard questionnaire used in UNRWA (21\% detection rate). In other words, almost one out of five needs psychological or mental health assistance, care and follow up; UNRWA has assisted all positive cases through psychosocial intervention and medication, as necessary. Cases that require advanced treatment are referred to secondary/ tertiary care institutions. Because the programme was integrated into the existing Family Health Team Approach, in which comprehensive care is provided to the entire family based on strong provider-patient relationships: patients can receive services in their regular community health centre from their regular doctor, an opportunity that has been well received. Moreover, stigma against mental health disorders among patients has decreased as the programme has expanded (4). Stigma against mental illness has been shown to have a negative impact on careseeking and worse treatment outcomes (5). The positive impact of this programme is encouraging for further expansion of the initiative.

This programme in UNRWA has demonstrated the effectiveness of the mhGAP and MHPSS programmes in resource-limited refugee communities and the synergistic effects of their integration into primary health care.

Overall, the programme has improved the mental wellbeing of Palestine refugees. However, several challenges 
still need to be overcome. The chronic shortage of doctors and other health staff is posing difficulties in providing adequate consultation times (6). Ensuring the privacy of patients is also a challenge in some health centres because of space limitations, issues which could be tackled with more resources. In addition, intersectoral support beyond health is needed as effective MHPSS programming requires coordination between diverse actors, including education, protection and social services (7).

Globally, mental health is set as a priority in the 2030 Agenda for Sustainable Development (8). In May 2019, the 72nd World Health Assembly approved "Promoting the health of refugees and migrants: Draft global action plan, 2019-2023" (9), which addresses the need to scale up mental health services. The plan requests Member States to support the development of national guidance designed to underpin the prevention and management of mental health conditions.

In light of this, it is critical to encourage serious commitment and investment by the global development community to achieve the mental health targets. Most refugee crises do not end quickly. Host countries in the Region and the organisations operating within them need to adopt long-term, sustainable solutions to respond to the mental health needs of refugees and displaced populations.

\section{References}

1. Charlson F, Ommeren M, Abraham Flaxman A, Cornett J, Whiteford H, et al. WHO prevalence estimates of mental disorders in conflict settings: a systematic review and meta-analysis. Lancet. 2019;394:240-8. http://dx.doi.org/10.1016/ So140-6736(19)30934-1

2. Mental health in emergencies. Cairo: World Health Organization Regional Office for the Eastern Mediterranean; 2019 (http:// www.emro.who.int/mnh/mental-health-in-emergencies/index.html, accessed 17 December 2019).

3. United Nations Relief and Works Agency for Palestine Refugees in the Near East (home page). Amman: 2021 (https://www. unrwa.org/resources/about-unrwa/unrwa-figures-2020-2021, accessed 8 December 2021.

4. Bruno W, Kitamura A, Najjar S, Seita A, Al-Delaimy WK. Assessment of mental health and psycho-social support pilot program's effect on intended stigmatizing behavior at the Saftawi Health Center, Gaza: a cross-sectional study. J Mental Health. 2019;28(4):436-42. https://doi.org/10.1080/09638237.2019.1608936

5. Corrigan PW, Druss BG, Perlick DA. The impact of mental illness stigma on seeking and participating in mental health care. Psycholog Sci Public Interest. 2014;15(2):37-70. doi:10.1177/1529100614531398

6. Annual report 2018. Amman: United Nations Relief and Works Agency for Palestine Refugees in the Near East (UNRWA), Department of Health; 2018.

7. Inter-Agency Standing Committee. IASC Guidelines on mental health and psychosocial support in emergency settings. Geneva: World health Organization; 2007.

8. Transforming our world: the 2030 Agenda for Sustainable Development. United Nations General Assembly, Seventieth Session. Agenda items 15 and 116; 25 September 2015. New York: United Nations; 2015 (A/RES/70/1; https://www.un.org/ga/search/view_ doc.asp?symbol=A/RES/70/1\&Lang=E, accessed 10 December 2019).

9. Promoting the health of refugees and migrants. Provisional agenda item 12.4; 25 April 2019. World Health Assembly, Seventy-Second Session. Geneva: World Health Organization; 2019 (WHA72.25; https://apps.who.int/gb/ebwha/pdf_files/WHA72/ A72_25-en.pdf, accessed 10 December 2019). 